\title{
PERANCANGAN SISTEM KEAMANAN WEBSITE DENGAN KONFIGURASI FILE.HTACCESS
}

\author{
Rico Septiandi ${ }^{1}$, Siti Madinah Ladjamuddin ${ }^{2}$, Ewin Suciana ${ }^{3}$ \\ Teknik Informatika - ISTN Jakarta ${ }^{1,2}$, Yayasan Al-Hikmah Citra Raya ${ }^{3}$ \\ J1 Moh Kahfi II, Srengseng Sawah, Jagakarsa ${ }^{1,2}$,Blok J11 No 21 Graha Lestari Citra Raya ${ }^{3}$ \\ septiandi.riko@gmail.com¹, citymadinah07@istn.ac.id², sucianaewin@gmail.com³
}

\begin{abstract}
Abstrak
Saat ini perkembangan teknologi informasi memainkan peranan yang sangat penting dalam berbagai aspek kehidupan, Internet merupakan jaringan komputer global di seluruh dunia sebagai media komunikasi dan informasi modern yang dapat memberikan serta menampilkan berbagai informasi dan data kepada publik. Sistem keamanan website dengan konfigurasi file.Htacces dibangun dengan tujuan untuk untuk melindungi website tersebut dari pencurian informasi yang sering terjadi pada saat ini. Sistem pengamanan ini sangat berguna untuk melindungi informasi dari serangan cracker. Karena pencurian data di Internet tidak dapat diketahui jika cracker tersebut mengambil informasi tanpa merusak sistem. Lain halnya dengan pencurian informasi yang sering terjadi dalam dunia nyata. Perancangan sistem keamanan webste ini dibuat dengan konfigurasi file.Htaccess dan Notepad ++. Tidak sedikit website yang menggunakan system otentikasi yang banyak di tembus oleh para cracker, mereka banyak mengincar website ini karena diduga menyimpan informasi yang rahasia. Perlu cara khusus dalam mengamankan website seperti ini. Dengan adanya sistem keamanan website menggunakan konfigurasi file.htaccess ini merupakan salah satu sarana untuk mengamankan halaman website.
\end{abstract}

Kata Kunci: Keamanan Website, File.Htaccess

\begin{abstract}
Currently the development of information technology plays a very important role in various aspects of life, the Internet is a global computer network around the world as a medium of communication and modern information that can provide and display various information and data to the public. Website security system with the configuration file.Htacces built with the aim to to protect the website from the theft of information that often occur at this time. This security system is very useful to protect information from cracker attacks. Because data theft on the Internet can not be known if the cracker is taking information without damaging the system. Another case with the theft of information that often occurs in the real world. The design of webste security system is made with the configuration file.Htaccess and Notepad ++. Not a few websites that use a lot of authentication system penetrated by the crackers, they are eyeing this website for allegedly storing confidential information. Need a special way in securing a website like this. With the website security system using the configuration file.htaccess this is one means to secure the website page.
\end{abstract}

Keywords: Website Security, File.Htaccess

\section{PENDAHULUAN}

\subsection{Latar Belakang}

Pada masa era globalisasi ini komputer sangat penting dalam kebutuhan informasi yang akurat, tepat dan cepat dalam menyajikan data yang sangat lengkap merupakan salah satu tujuan penting. Dengan peningkatan kebutuhan akan informasi di dunia maya membuat para developer website berlomba-lomba menyajikan berbagai macam layanan sehingga para pengguna akan betah berkunjung ke dalam websitenya. Dari masa-masa ke masa teknologi website mengalami perkembangan yang begitu pesatnya dan kini bahkan memberalihkan aplikasi dektop yang selama ini kita kenal menjadi aplikasi berbasis web. Selain itu tidak sedikit diantara pengguna internet yang memanfaatkan traffic pengguna internet tersebut. Dari mulai bisnis online ataupun yang lainnya. 
Website merupakan halaman yang dibangun untuk menyampaikan sebuah informasi. Ada banyak website yang tersedia di internet, dari mulai website personal hingga website milik pemerintahan. Informasi yang disampaikan pun beragam, ada yang sekedar menyampaikan informasi kepada seluruh pengunjung ada juga yang menggunakan system otentikasi dalam menyampaikannya. Tidak sedikit website yang menggunakan system otentikasi yang banyak di jebol oleh para cracker, mereka banyak mengincar website ini karena diduga menyimpan informasi yang rahasia. Perlu cara khusus dalam mengamankan website seperti ini. Dari uraian diatas maka timbul keinginan untuk membahas dan merancang suatu sistim yang dapat mengamankan website seperti tersebut.

\subsection{Tujuan Penelitian}

Tujuan penelitian ini untuk memberitahukan cara mengamankan halaman administrator menggunakan konfigurasi file.Htaccess, sehingga pengguna internet dapat melindungi website mereka dari serangan cracker.

\section{LANDASAN TEORI}

\subsection{Metode Penelitian}

\section{Analisa Perancangan Sistem}

\section{Analisa Sistem}

Seiring dengan perkembangan teknologi informasi saat ini serta untuk meningkatkan efesiensi kerja dan waktu, dalam mempermudah pekerjaan itu banyak cara yang dapat digunakan dalam menyampaikan sebuah informasi kepada seseorang. Salah satunya dengan media internet jika berbicara internet, kita tidak pernah bisa melepaskan kaitan antara internet dengan sebuah website.

Website merupakan halaman yang dibangun untuk menyampaikan sebuah informasi tapi belakangan ini para pemilik website merasa khawatir terhadap halaman serta informasi mereka di internet karena keberadaan para cracker yang pada umumnya mencari informasi penting dalam website tersebut dan mengambil alih kepemilikan website tersebut. Adapula yang hanya merubah tampilan halaman utama dari website tersebut. Tidak sedikit memang yang telah menjadi korban akibat ulah para cracker ini. Untuk memulai membangun suatu program mengenai sistem keamanan halaman website dengan mengunakan konfigurasi file htaccess maka merencanakan alur kerja berdasarkan kebutuhan suatu website yang akan menggunakan sistem keamanan ini.

\section{Analisa Sumber Daya}

Dalam analisa ini berisi mengenai sumber daya yang dibutuhkan untuk merancang sistem keamanan halaman admin dengan konfigurasi file .htaccess, dilihat dari kebutuhan sumber daya perangkat keras, perangkat lunak serta alat penguji yang dibutuhkan dalam penelitian ini.

\section{Analisa Perangkat Keras}

Tabel-1 Spesifikasi Perangkat Keras

\begin{tabular}{|c|c|}
\hline Perngkat & Spesifikasi \\
\hline Processor & Intel® inside CPU@ 1.6Ghz \\
\hline RAM & $4096 \mathrm{MB}$ \\
\hline Harddisk & 259 \\
\hline
\end{tabular}

\section{Analisa Perangkat Lunak}

Tabel-2 Spesifikasi Perangkat Lunak

\begin{tabular}{|c|c|}
\hline Perangkat Lunak & Yang Digunakan \\
\hline Sistem Operasi & Windows 8 \\
\hline Web Browser & Mozzila Firefox \\
\hline Code Editor & Notepad ++ \\
\hline
\end{tabular}

\subsection{Alat Pengujian}

\section{Analisa Sistem Berjalan}

Menganalisa suatu sistem yang sedang berjalan merupakan salah satu tahap untuk manganalisa suatu sistem akankah sesuai dengan tujuan utama sistem itu sendiri yaitu mengamankan halaman admin pada suatu website. 
Analisia sistem dalam suatu perancangan sangat penting karena fungsi dari analisia itu sendiri yaitu untuk mengetahui bagaimana sistem itu berjalan agar sistem yang dibuat dapat menghasilkan output yang diinginkan dan dapat mencapai tujuan yang direncanakan.

\section{Kode File.Htaccess Berjalan}

Pada file .htaccess yang sedang berjalan ini masih belum ada kode keamananya dan masih berisi suatu komen yang sudah disediakan.

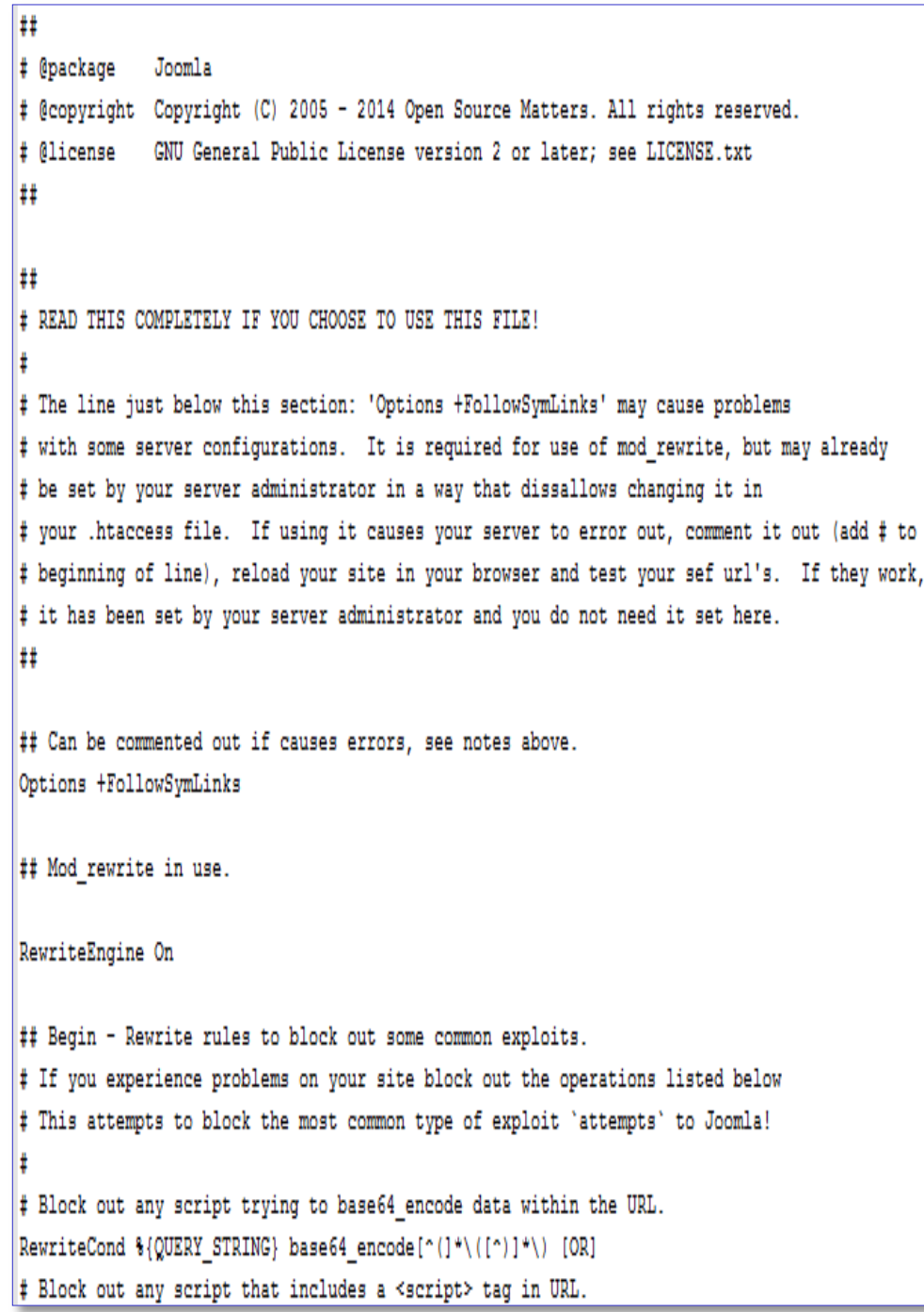

\subsection{Analisa Sistem Usulan}

Gambar-1 Kode file .Htaccess Berjalan.

Analisa system usulan adalah dimana analis system mengidentifikasikan masalah- masalah kebutuhan pemakai, menyatakan secara spesifik sasaran yang harus dicapai untuk memenuhi kebutuhan pemakai, masalah alternative, metode pemecaha yang paling tepat, merencanakan dan menerapkan rancangan systemnya.

\section{Kode File.Htaccess Usulan}

Mengetahui kendala yang ada, maka dirancang sebuah sistem keamanan halaman website menggunakan konfigurasi file.htaccess dengan memasukan beberapa kode perintah pada file.Htaccess 


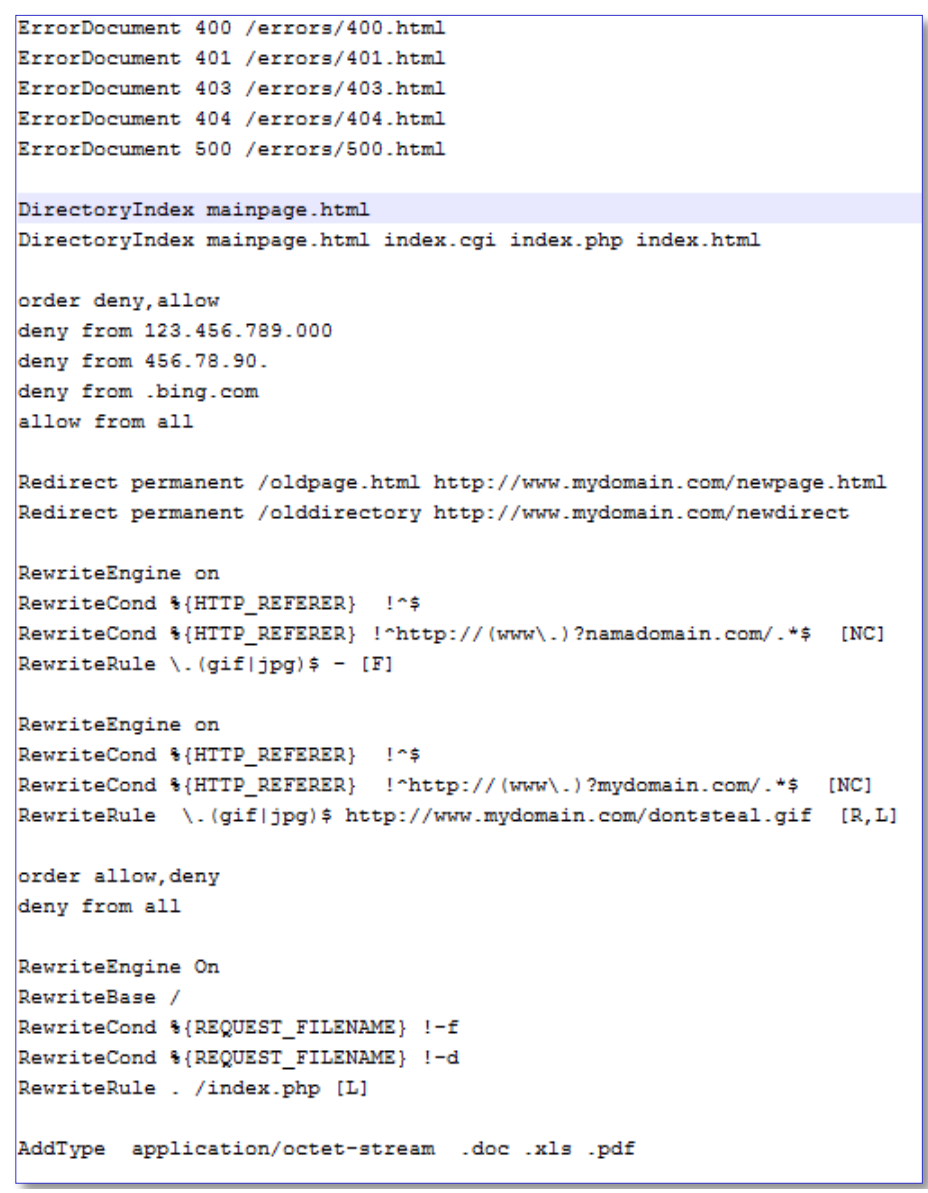

\section{Perancangan}

Gambar-2 Tampilan Halaman Website Usulan

Perancangan dilakukan 2 langkah penelitian, dimana langkah pertama untuk melakukan penelitian web sebelum mengimplementasikan sistem dan langkah ke 2 untuk web yang telah diterapkan sistem keamanan.

\section{Langkah Pertama}

Dalam tahap ini, web target diuji coba sistem keamanan yang ada. Penelitian ini dilakukan untuk mendapatkan data dengan alat pengujian terhadap web yang belum diimplementasikan sistem keamanan baru. Data tersebut berupa hasil keamanan yang diterapkan dalam website tersebut.

\section{Langkah Kedua}

Dalam tahap ini diimplementasikan sistem keamanan yang baru terhadap web, tahap implementasi ini meliputi

a. Implementasi secara internal

b. Optimasi secara eksternal

Setelah melakukan tahap implementasi, dilakukan analisa menggunakan alat penguji yang sama dengan tahap pertama, yaitu penggunaan search engine secara langsung serta khususnya analisa terhadap sistem keamanan dalam website tersebut. Setelah melakukan penelitian dalam dua tahap, dilakukan pembahasan terhadap hasil pengujian baik pengujian pada tahap pertama maupun pada tahap kedua.

Metode Sistem Keamanan Website

Dalam penelitian ini menggunakan dua penerapan metode Sistem Keamanan Website. Dua penerapan tersebut adalah penerapan secara internal dan penerapan secara eksternal.

\section{Penerapan Sistem Secara Internal}

Penerapan metode Sistem secara internal dilakukan untuk keamanan dari sisi web itu sendiri.

\section{Penerapan Dengan .Htaccess}


Dalam penerapan metode sistem ini akan dilakukan teknik-teknik yang dapat membuat sebuah url menjadi :

- Mem-proteksi Folder / Melindungi Folder dengan password

- Mengalihkan pengunjung website dengan otomatis

- Membuat halaman pesan tampilan error

- Menolak pengunjung dengan IP Address tertentu

- Merubah extensi file

- Hanya mengijinkan pengunjung dengan IP Address tertentu

- Mengijinkan/Menolak list direktori

\section{Penerapan Sistem Keamanan Secara Umum}

Disamping menerapkan metode sistem editor file htaccess, juga di terapkan metode lain. Namun penerapan ini hanya sebagai pelengkap saja, Metode tersebut antara lain adalah sebagai berikut :

- Password Direktori

- Instalasi Modul URL Rewrite

\section{Penerapan Metode SEO Secara Eksternal}

Metode SEO secara eksternal dilakukan di luar website, ini dimaksudkan untuk membantu keamanan secara internal. Metode secara eksternal adalah sebagai berikut :

\section{Penggunaan Google Webmaster Tool}

Google web master adalah fasilitas yang disediakan oleh google dalam optimalisasi dan keamanan website. Google web master sangat membatu untuk melengkapi optimalisasi serta keamanan web dari internal web.

\section{HASIL DAN PEMBAHASAN}

\subsection{Implementasi Sistem}

Setelah dianalisis dan dirancang secara rinci dan teknologi telah diseleksi dan dipilih. Tiba saatnya, sistem untuk di implementasikan. Implementasi sistem adalah langkahlangkah atau prosedur yang dilakukan dalam menyelesaikan desain sistem yang telah disetujui, untuk menguji, menginstal, dan memulai sistem baru atau sistem yang diperbaiki untuk menggantikan sistem yang lama, sedangkan tahap implementasi sistem merupakan tahap meletakkan sistem agar sistem dapat siap untuk dioperasikan. Tahap implementasi sistem terdiri dari langkah-langkah sebagai berikut ini :

1. Menerapkan rencana implementasi

2. Melakukan kegiatan implementasi

3. Tindak lanjut implementasi

\subsection{Tujuan Implementasi}

1. Mengkaji rangkaian sistem baik dari segi software maupun hardware sebagai sarana pengolah data dan penyaji informasi.

2. Menyelesaikan rancangan sistem yang ada dalam dokumen sistem yang baru atau yang telah disetujui.

3. Memastikan bahwa pemakai dapat mengoperasikan dengan mudah terhadap sistem yang baru dan mendapat informasi yang baik dan jelas.

4. Memperhitungkan bahwa sistem telah memenuhi permintaan pemakai yaitu dengan menguji sistem secara menyeluruh.

5. Memastikan bahwa sistem telah berjalan lancar dengan mengontrol dan melakukan instalasi secara benar.

\section{Implementasi Input Kode}

\section{Custom HTTP Error}

1. Buka file htaccess yang telah di download menggunakan notepad++ 


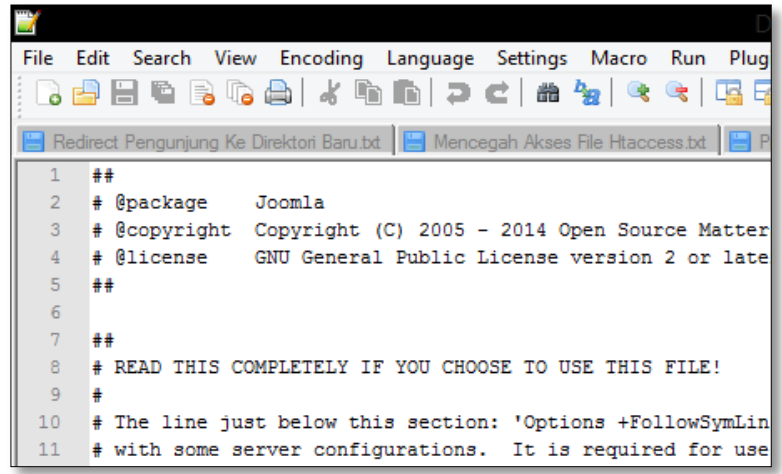

Gambar 3 Editor File Htaccess

2. Ketikan script berikut dalam baris terakhir file htaccess

$\begin{array}{lll}\text { Errordocument } 400 & \text { /errors/400.html } \\ \text { Errordocument } 401 & \text { /errors/401.html } \\ \text { Errordocument } 403 & \text { /errors/403.html } \\ \text { Errordocument } 404 \text { /errors/404.html } \\ \text { Errordocument } 500 \text { /errors/500.html }\end{array}$

Gambar 4 Script Custom HTTP Error

Gambar diatas menjelaskan penambahan script untuk memberikan informasi pesan error pada sebuah website sangat penting karena bisa membantu para pengunjung dalam mengetahui apa yang sedang terjadi. Dengan file .htaccess kita dapat mengubah halaman error pada server, dengan mendefinisikan sesuai dengan keinginan kita sendiri.

\section{Change Default Home Page}

1. Buka file htaccess yang telah di download menggunakan notepad++

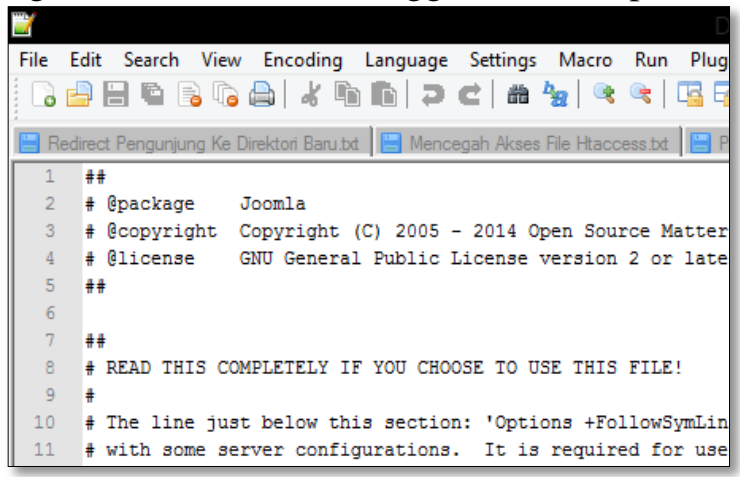

Gambar 5 Editor File Htaccess

2. Ketikan script berikut dalam baris terakhir file htaccess

DirectoryIndex mainpage. $\mathrm{html}$
DirectoryIndex mainpage. $\mathrm{html}$ index.cgi index.php index.html

Gambar 6 Script Change Default Home Page

Kondisi ini menunjukkan bahwa file .htaccess dapat digunakan untuk mengubah nama default halaman depan web. Agar user bisa mengakses website kita hanya dengan nama domain saja (http://www.nama_web.com) tanpa harus menulis nama file secara jelas (http:www.nama_web.com/file.html), kita harus mempunyai file index di root direktori. Nama file yang bisa diterima antara lain index.html, index.htm, index.cgi, index.php dll. Pastikan bahwa file tsb bernama index.* Ada tingkatan dalam pemberian nama tersebut. Jika kita punya index.cgi \& index.html di root direktori maka server akan menampilkan index.cgi karena .cgi memiliki tingkatan yang lebih tinggi daripada $\cdot$ html

Dengan .htaccess, kita bisa mendefinisikan file index tambahan atau bisa juga mengubah urutan tingkatannya. Untuk mendefinisikan mainpage.html sebagai halaman index, kita dapat menambahkan kode berikut ke file .htacces : DirectoryIndex mainpage.html

Hal ini akan membuat server mencari file bernama mainpage.html. Jika server menemukannya maka server akan menampilkannya. Tapi bila tidak, maka server akan menampilkan error 404 Missing Page. Untuk mengubah urutan tingkatan, kita dapat memasukkan perintah 
DirectoryIndex dengan nama-nama file dalam satu baris. Urutan penulisan file tersebut menentukan urutan tingkatan, contohnya:

DirectoryIndex mainpage.html index.cgi index.php index.html

\section{Block Users From Accessing Your Website}

1. Buka file htaccess yang telah di download menggunakan notepad++

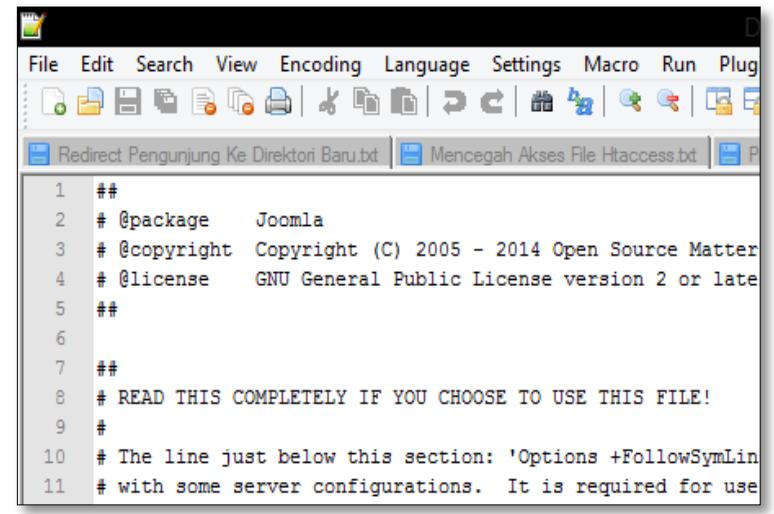

Gambar 7 Editor File Htaccess

2. Ketikan script berikut dalam baris terakhir file htaccess

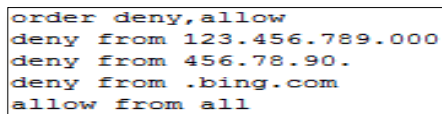

Gambar 8 Script Block Users From Accessing Your Website

Jika kita menginginkan mem-blok access untuk beberapa user, dimana kita mengetahui IP / domainname yang digunakannya, kita dapat menambahkan kode berikut :

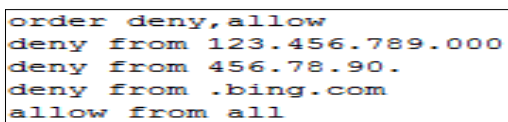

Pada contoh di atas, user dg IP 123.456.789.000 akan diblok. Semua user antara 456.78.90.000 sampai 456.78.90.999 akan diblok. Dan semua user yang berasal dari bing.com akan diblok. Jika mereka mencoba mengakses website kita, maka akan tampil error 403 Forbidden ("You do not have permission to access this site")

Redirect Pengunjung Ke Direktori Baru

1. Buka file htaccess yang telah di download menggunakan notepad++

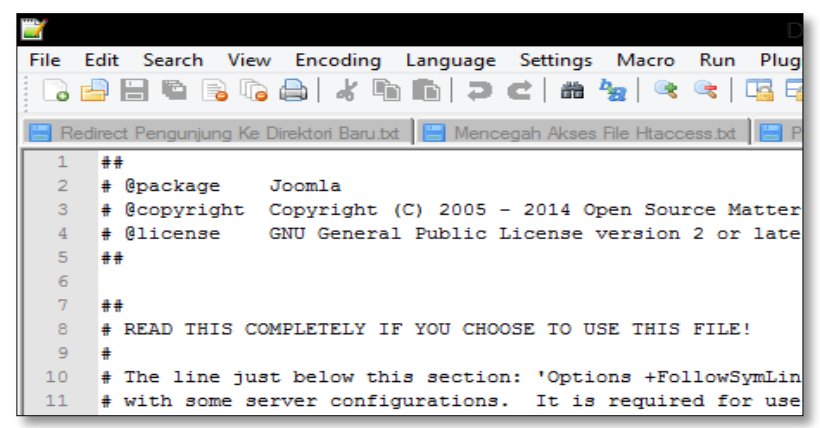

Gambar 9 Editor File Htaccess

2. Ketikan script berikut dalam baris terakhir file htaccess Redirect permanent /oldpage.html http://ww. mydomain.com/newpage.html Redirect permanent /olddirectory http://ww. mydomain.com/newdirect

\section{Gambar 10 Script Redirect}

Misalkan kita membuat ulang seluruh website kita, me-rename halaman \& direktori. Maka pengunjung halaman lama akan mendapat error 404 File Not Found. Masalah tersebut dapat diatasi dengan melakukan redirect dari halaman lama ke halaman yang baru. Contohnya bila halaman lama kita adalah oldpage.html dan halaman baru adalah newpage.html maka perintahnya adalah: 
Redirect permanent /oldpage.html http://www.mydomain.com/newpage.html Jika kita me-rename (mengganti nama) direktori, maka perintahnya adalah:

Redirect permanent /olddirectory http://www. mydomain.com/newdirect

Perhatikan bahwa nama direktori yang lama ditulis dengan relative path, sementara yang baru ditulis dengan URL absolut

\section{Prevent Hot Linking and Bandwidth Leeching}

1. Buka file htaccess yang telah di download menggunakan notepad++

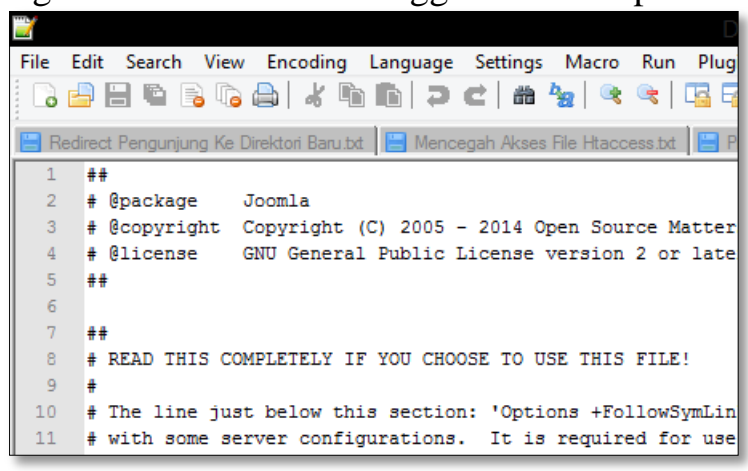

Gambar 11 Editor File Htaccess

2. Ketikan script berikut dalam baris terakhir file htaccess

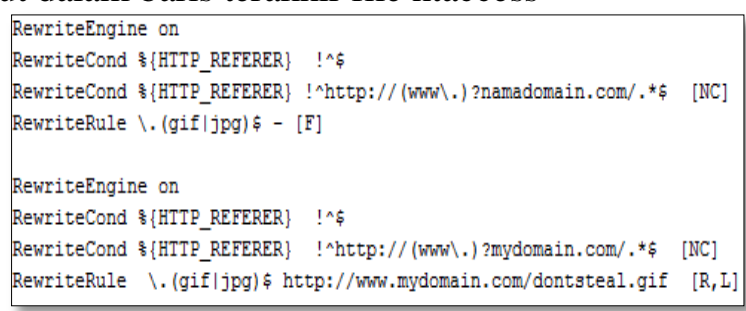

Gambar 12 Script Hot Linking and Bandwidth Leeching

Untuk mencegah orang lain me-link secara langsung ke direktori image anda dari website mereka, biasanya ada orang mengambil gambar dari website kita, tapi tetap menggunakan link diserver host kita, ini tentu akan merugikan bagi kita karena dapat mengurangi bandwith di hosting kita, untuk mengatasi hal ini kita dapat menambahkan kode berikut:

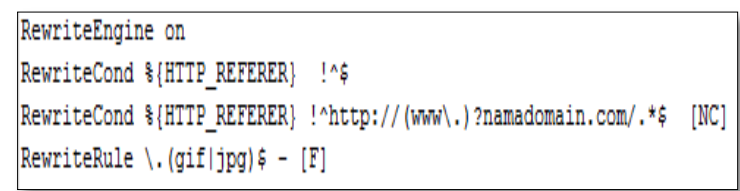

Perintah tersebut akan membuat direktori image hanya bisa diakses bila user sedang mengakses www.namadomain.com Jika kita merasa jengkel, kita bisa membuat sebuah image alternatif bila direktori image di-link oleh orang lain. Contohnya kita membuat image alternatif dengan nama nogambar.gif yang bertuliskan: "Gambar dari web lain kunjungi http://namadomain.com untuk melihat gambar sebenarnya." Maka kita dapat menambahkan kode berikut:

\begin{tabular}{|c|c|}
\hline \multicolumn{2}{|l|}{ RewriteEngine on } \\
\hline RewriteCond \& \{HTTP_REFERER\} & 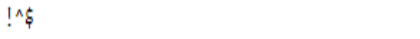 \\
\hline RewriteCond $\&\{$ HTTP_REFERER\} & !^http://(www).) ?mydomain. com/.*\$ [NC] \\
\hline RewriteRule 1. (gif $\mid$ jpg) \$ ht & cp://ww,mydomain, com/dontsteal, gif $[R, L]$ \\
\hline
\end{tabular}

\section{Mencegah Akses File Htaccess}

1. Buka file htaccess yang telah di download menggunakan notepad++ 


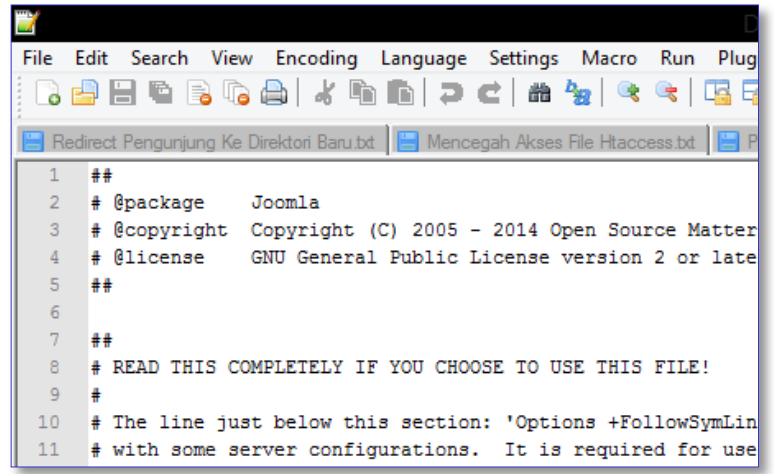

Gambar 13 Editor File Htaccess

2. Ketikan script berikut dalam baris terakhir file htaccess

order allow, deny
deny from all

Rewriting URLs

Gambar 14 Script Mencegah Akses File Htaccess

1. Buka file htaccess yang telah di download menggunakan notepad++

\begin{tabular}{|l}
\hline File Edit Search View Encoding Language Settings Macro Run Plug \\
\hline 1
\end{tabular}

Gambar 15 Editor File Htaccess

2. Ketikan script berikut dalam baris terakhir file htaccess

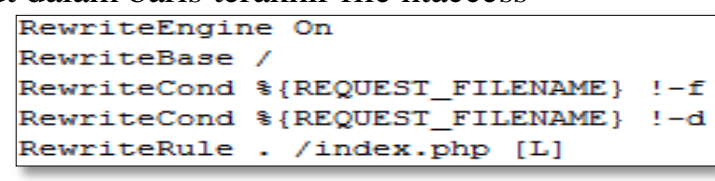

Gambar 16 Script Rewriting URLs

Agar kita dapat melakukan pengaturan pada permalink kita agar lebih SEO friendly kita dapat menambahkan kode berikut ini:

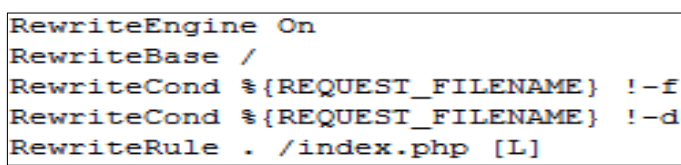

MIME Types

1. Buka file htaccess yang telah di download menggunakan notepad++ 


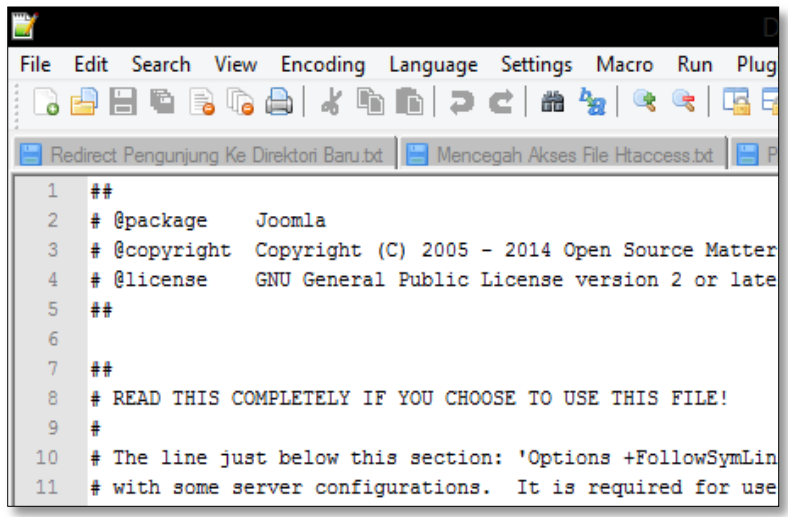

Gambar 17 Editor File.Htaccess

2. Ketikan script berikut dalam baris terakhir file htaccess

$$
\text { AddTye application/octet-stream .doc .xls .pdf }
$$

Gambar 18 Script Rewriting URLs

Memerintahkan server untuk mengenali jenis file-file yang belum didaftarkan dalam sistem server. Contohnya :

$$
\text { AddType application/octet-stream .doc .xls .pdf }
$$

\section{Cache Control}

1. Buka file htaccess yang telah di download menggunakan notepad++

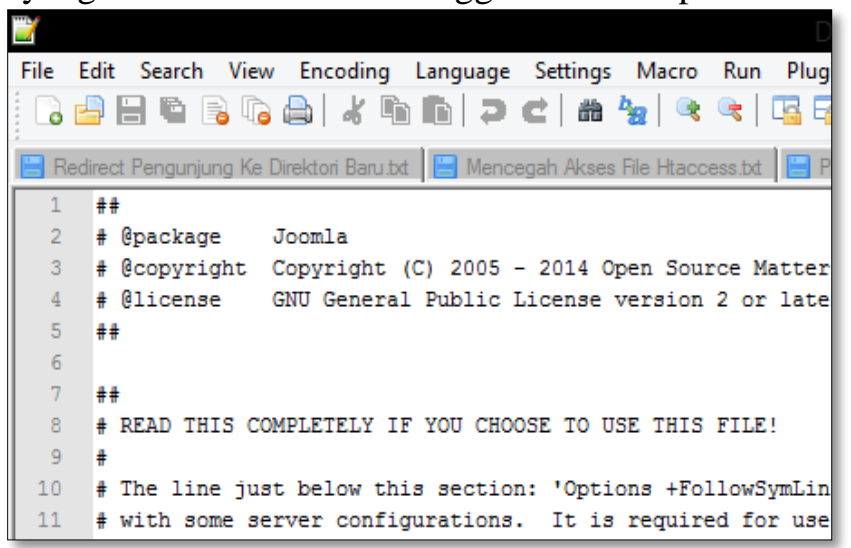

Gambar 19 Editor File Htaccess

2. Ketikan script berikut dalam baris terakhir file htaccess

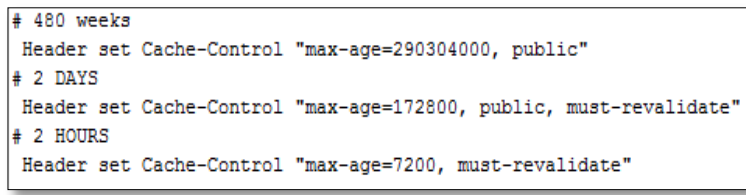

Gambar 20 Script Cache Control

File htaccess bisa mengendalikan caching pada web browser sehingga dapat mengurangi penggunaan bandwidth atau aktivitas yang ada didalam server. Contohnya:

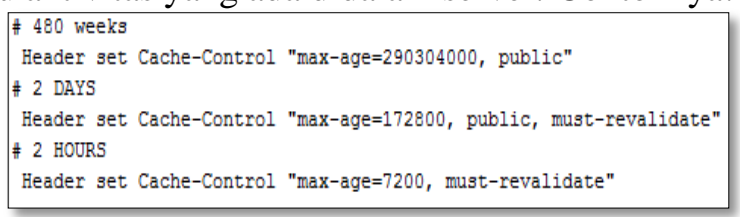

\section{Save File Htaccess}

1. Save as file htaccess yang telah di edit menggunakan editor notepad ++ 
2. Isikan

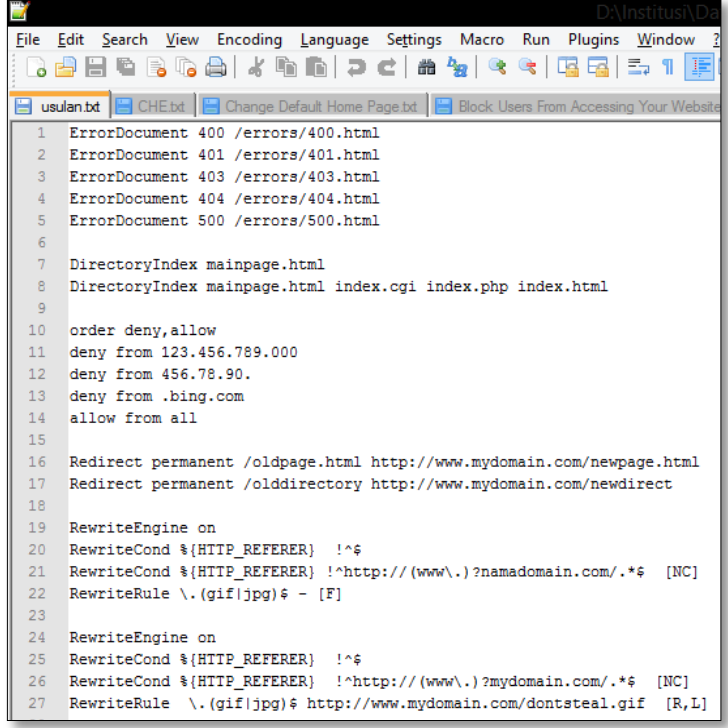

Gambar 20 Editor File Htaccess

File Name

: htaccess

Save As Type

: All Types

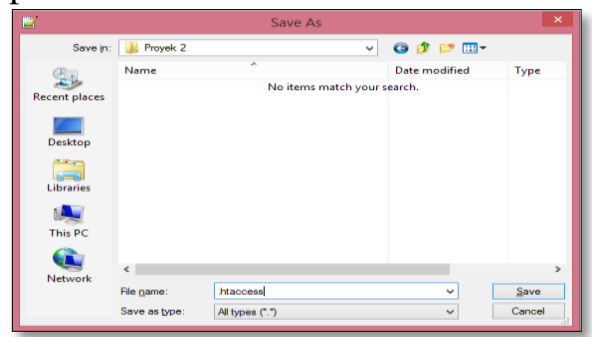

Gambar 21 Save As File .htaccess

\section{Upload File .htaccess}

1. Lakukan login ke cpanel hosting website objek.

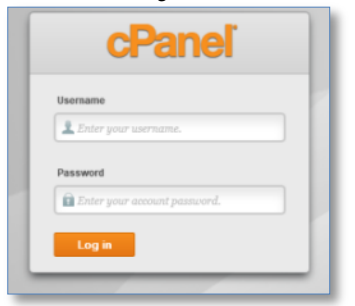

Gambar 22 Login Cpanel

2. Masukan username dan password

Username : riko

Password: teknikinformatika12

3. Setelah sukses login dan masuk ke cpanel, masuk ke menu file manager untuk melihat direktori website objek 


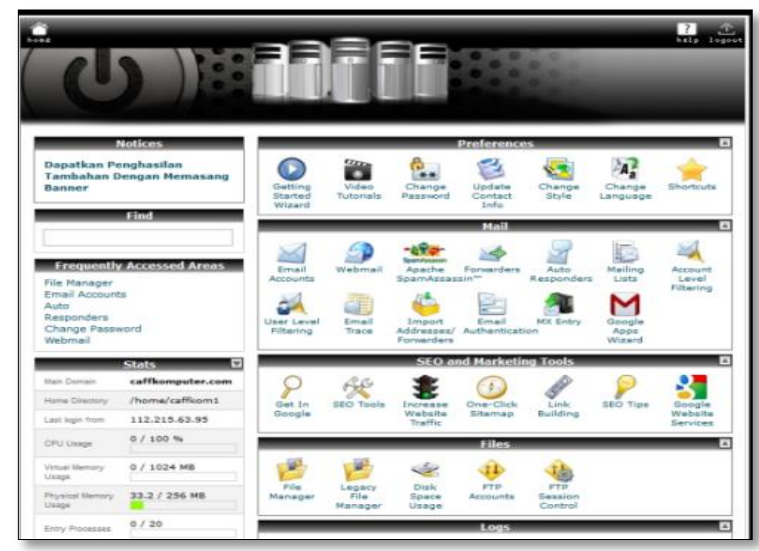

Gambar 23 Home Cpanel Website Objek

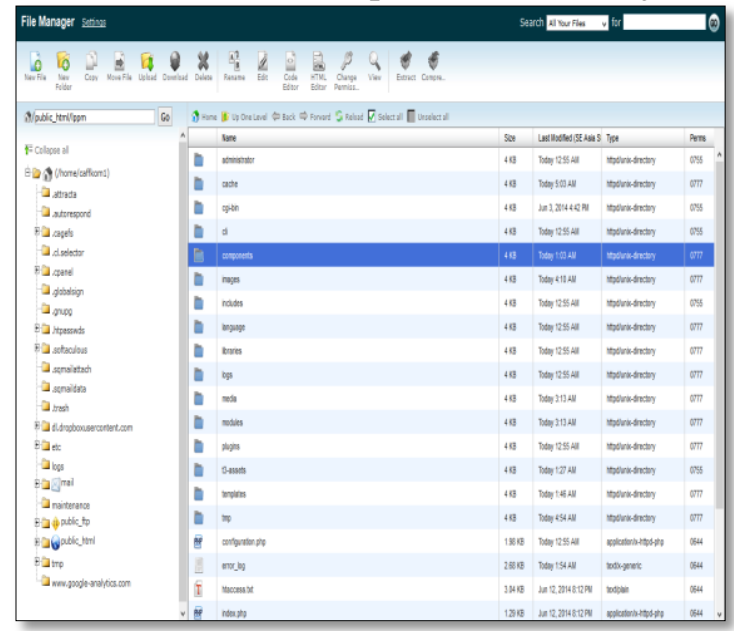

Gambar 24 File Manager Website Objek

4. Pilih menu upload untuk mengupload file .htaccess yang telah diedit.

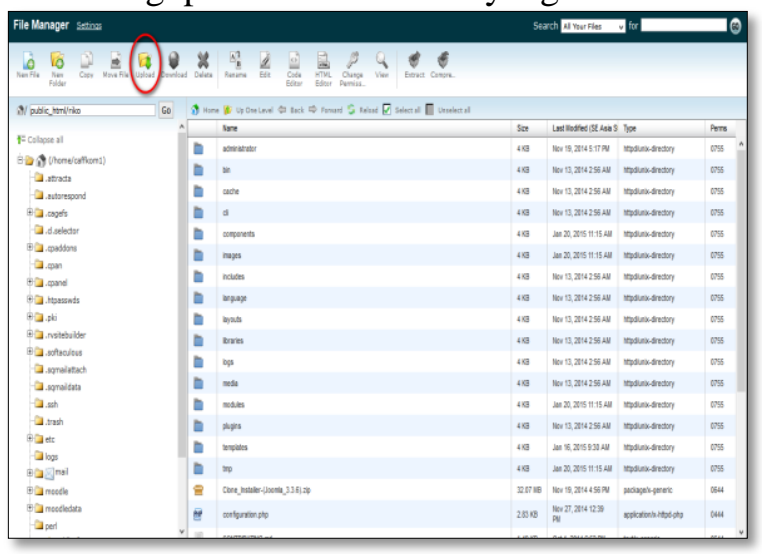

Gambar 25 Proses 1 Upload File .htaccess

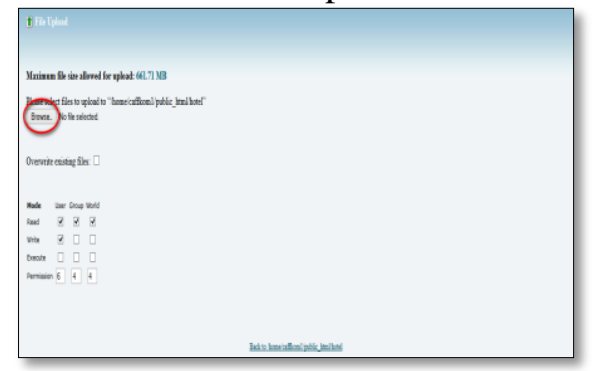

Gambar 26 Proses 2 Upload File .htaccess 


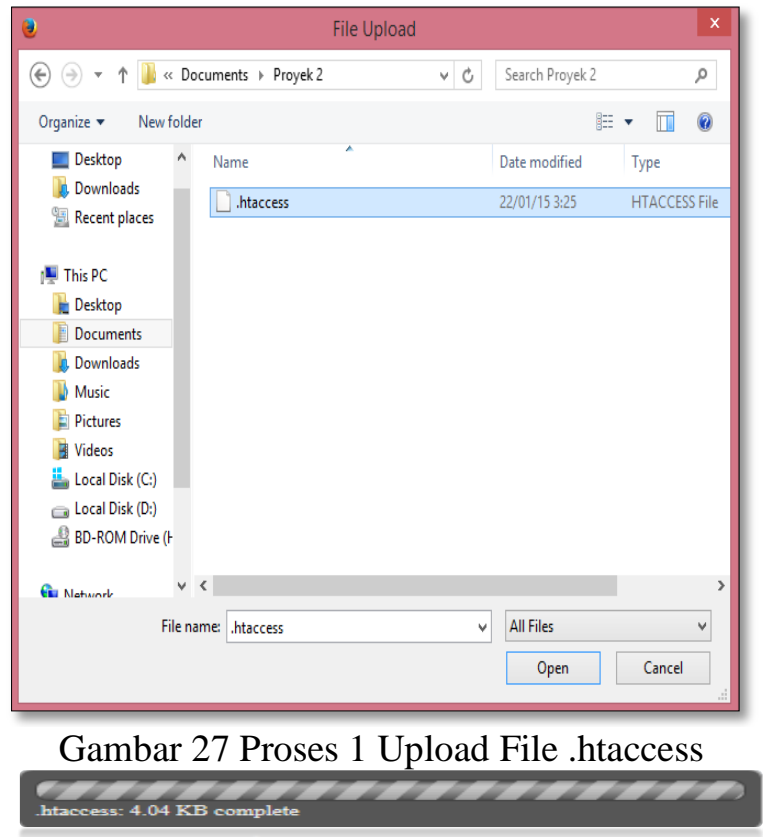

Gambar 28 Upload File .htaccess Selesai

5. Lalu hapus file Htaccess

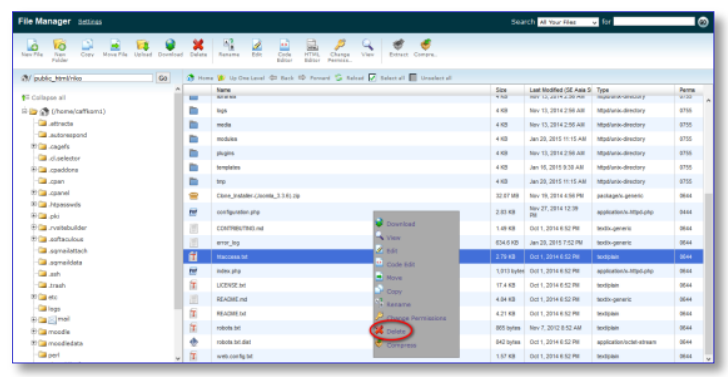

Gambar 29 File Htaccess di Hapus

\section{KESIMPULAN DAN SARAN}

\subsection{Simpulan}

Sistem keamanan website yang dibangun menggunakan file.htaccess dapat melindungi website dari pencurian informasi dan dari serangan cracker yang sering terjadi pada saat ini.

\subsection{Saran}

Dalam pengaman website menggunakan file htaccess ini masih banyak kekurangan. Oleh sebab itu penulis mengharapkan untuk kedepannya dapat dikembangkan lebih baik lagi agar bisa menjadi sistem keamanan yang sempurna.

\section{DAFTAR PUSTAKA}

[1]. Slamet Riyanto. 2014. Web Dinamis dengan PHP dan MySQL. Penerbit Selamet Riyanto

[2]. Tim EMS. 2011. Proyek Membuat Website dengan Joomla. Jakarta: Penerbit PT. Elex Media Komputindo.

[3]. Sugiri, 2012. Desain Web menggunakan HTML + CSS. Jogjakarta: Penerbit Andi Offset Jogjakarta.

[4]. Th0R. 2008. Hacker's Biggest Secret Zero-knowledge Password. Jakarta: Penerbit PT. Elex Media Komputindo.

[5]. Fritz Gamaliel. 2014. Super Web Programming 10 Bahasa 10 Proyek Web. Yogyakarta: Penerbit Loko Medi

[6]. Jamie Cameron. 2004. Managing Linux Systems with Webmin System Administration and Module Development. Penerbit Prentice Hall Professional 